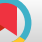

\title{
Assessment of the Awareness of Radiology Residents About Ionizing Radiations and Their Risks of Educational Hospitals, Kermanshah,
}

\section{Iran}

\author{
Sogand Abbasi Azizi ${ }^{1}$, Mohammad-Rasoul Tohidnia ${ }^{2}$ and Mohsen Zhaleh ${ }^{3, *}$ \\ ${ }^{1}$ Student Research Committee, Kermanshah University of Medical Sciences, Kermanshah, Iran \\ ${ }^{2}$ Radiology and Nuclear Medicine Department, Paramedical School, Kermanshah University of Medical Sciences, Kermanshah, Iran \\ ${ }^{3}$ Department of Anatomical Sciences, School of Medicine, Kermanshah University of Medical Sciences, Kermanshah, Iran \\ "Corresponding author: Department of Anatomical Sciences, School of Medicine, Kermanshah University of Medical Sciences, Kermanshah, Iran. Emails \\ zhaleh.mohsen@gmail.com; m_zhaleh@kums.ac.ir
}

Received 2021 November 10; Revised 2021 December 17; Accepted 2021 December 19.

\begin{abstract}
Background: Although many radiological examinations are requested daily to aid clinical diagnosis by the referring physician, it should be kept in mind that ionizing radiation has adverse biological effects on the life of living organisms, which may vary in individuals depending on the dose and duration of exposure. Therefore, radiologists and their assistants should have comprehensive information about ionizing radiation.

Methods: In this descriptive cross-sectional study, all the radiology residents (41) were included in the study. The questionnaire consisted of two parts, the first part including of demographic information and part 2 includes 21 questions about the effective dose created by a chest X-ray, the approximate effective dose from various imaging examines, as well as the awareness of the risks of brain, abdominal CT scans.

Results: The results showed that out of 41 residents, $56.1 \%$ were male. Based on these results, $19.5 \%$ were aware of the approximate effective dose received by a patient on PA chest X-ray. Also, knowledge of some X-ray absorptiometry parameters based on chest X-ray in PA position are: $12.2 \%$ abdominal CT scan, $17.1 \%$ and $2.4 \%$ brain and chest CT scan respectively. In this study the radiology resident's awareness about dangers of ionizing radiation and the likelihood of cancer were evaluated in $31 \%$ and $48.8 \%$ of brain and abdominal CT scan, respectively.

Conclusions: According to the findings, awareness of radiology residents in Kermanshah university of medical sciences is at an inappropriate level. Therefore, training is needed to raise the awareness of radiology residents by conducting several workshops.
\end{abstract}

Keywords: Ionizing Radiation, Resident of Radiology, Radiation Protection, Radiology Unit

\section{Background}

Nowadays, radiology plays a significant role in modern medicine, and many interventional and diagnostic imaging techniques are performed using ionizing radiation. In 2009, an international consul reported a 7-fold increase in ionizing radiation exposure to the USA population for diagnostic purposes since 1980 (1). Although, many daily radiology examinations had been requested by a referring physician to help clinical diagnosis $(2,3)$; but it should be kept in mind that ionizing radiation has negative biological effects on the life of living organisms, that may increase the potential risks of lifetime cancer occurrence in individuals depending on the dose and duration of exposure to X-rays and therefore is a threat to public health $(4,5)$, because a lower threshold radiation dose doesn't reveal adverse out- comes for at least 1 - 2 decades (1). Over the past years, numerous studies have been conducted on the level of global knowledge about ionizing radiation in general practitioners and specialists in medicine, medical students, trainees and teaching assistants and results show that the information and knowledge about ionizing radiation and its potential risks are very limited $(1,2)$; for example in a study by Zakeri et al. in 2016, it is found that only 33\% of 136 general and specialist practitioners (different disciplines) were aware of effective dose rates created by X-ray (6). In another study conducted by Ramanathan and Ryan in 2014 , it turned out that $23 \%$ of total 92 radiology residents working in the medical imaging department were aware of the dose rate and its risks (1). Another study conducted in 2013 in Turkey aimed to compare the information level 
of 300 radiology residents, interns and radiographers in emergency departments showed that unfortunately, radiology residents with a response rate of $39.4 \%$ had the least information (7). In brief, it is important that referring physicians have comprehensive information about ionizing radiation and its possible risks, since they are one of the prescribers for radiology examinations and, after those, it is most important for radiologists because they have an important task to decide on the requested test according to the patient's history and status, and they have to response patient questions (1); therefore, radiologists and their assistants need to have a high level of knowledge and information about ionizing radiation and their potential risks (8). Since there has not been any research on the awareness of radiology residents about ionizing radiation and its complications in Kermanshah. In this study, the researchers intended to provide a picture of the current state of this group's awareness so that, based on the results of this study, some plans can be made to improve educational quality and adopt appropriate strategies if necessary.

\section{Methods}

In this descriptive cross-sectional study, the awareness of radiology residents about ionizing radiation and its potential risk was investigated. The study population consisted of all radiology residents studying in Kermanshah medical education centers in 2018 - 2020 who totally were 41 individuals and were studied by census method. The questionnaire completed by radiology residents in hospitals was designed by the researcher so that the validity of the questionnaire was confirmed by 4 faculty members and the reliability of the questionnaire was calculated by using Cronbach's alpha coefficient to be 0.78 after distributing 10 questionnaires among statistical population and executing repeated tests. The coefficient of agreement between the two tests was 0.96 showing that it is an acceptable agreement. The way the variables are scored is based on the Zero-one (true/false) Scale. The questionnaire consisted of two parts, the first part covering demographic information through 9 questions (age, gender, date of obtaining general medical degree, name of university where general medical degree was taken, length of residency, history of attending radiation protection workshops) and part 2 includes 21 questions (Supplementary File) about the knowledge of background radiation amount, the effective dose created by a chest X-ray (PA) test, the approximate effective dose of various imaging examinations including brain, abdominal and pelvic CT scans, Barium meal, transit and etc.; also awareness of the risk of brain, abdominal and pelvic CT scans and having information about the difference in radiation parameters between children and adults.
After completing the questionnaire by radiology residents and collecting them, data were entered in KSOI STATA 12 software and frequency, percentage, mean and standard deviation for the variables were analyzed. Qualitative variables were reported based on frequency table and quantitative variables were reported based on mean and standard deviation. The sum of the scores obtained by individuals from question 1-17 was considered as the score of individual awareness of ionizing radiation. So, to get the average, we divided the sum of these scores for all people by the number of people studied. In the same way, based on questions 17 -21, we have gained awareness of the possible dangers of ionizing radiation. Inadequate or incomplete response of radiology residents to questionnaire questions was one of the limitations of this study.

\section{Results}

The purpose of this study was to determine the awareness of radiology residents of Kermanshah university of medical sciences about ionizing radiation and its potential risk in 2018 - 2020. The results of the study on gender frequency show that out of 41 individuals, 23 (56.1\%) were male and 18 (43.9\%) were female. Findings from the descriptive statistics regarding the age of residents show that the average age of the residents is 31.17 years with a standard deviation of 5.57. The youngest among residents was 25 years old and the oldest was 56 years old. According to results Table 1 , we find that the frequency distribution related to the year of obtaining the general medical degree shows that in 2012 and 2014 the highest number of degrees was obtained. Based on the Table 2 the results showed the descriptive statistics related to the length of the residency period. Regarding the necessity of training courses on ionizing radiation just 1 subject (2.4\%) has passed a training course on the dangers of using imaging techniques during residency (based on the answer to question 7 of the demographic part) and resident's opinion about training courses was evaluated and 39 residents (95.1\%) agreed to attend training course on the dangers of using imaging techniques, 27 residents (65.9\%) agree to attend training courses during residency(Table 3). In the second part of the questionnaire, the level of knowledge of all radiology assistants about ionizing radiation was investigated. This section consisted of 21 (17 and 4) questions. According to the information obtained from the questionnaire, the descriptive statistics of the radiology resident's knowledge about ionizing radiation are as follows Table 4.

Based on the results, the number of research units (residents) was 41 people. Average knowledge score of residents was 4.14 out of 17 with a standard deviation of 2.98. Of the 17 questions related to awareness, the highest reported 


\begin{tabular}{lcc}
\hline $\begin{array}{l}\text { Table 1. Frequency Distribution Related to the Year of Obtaining the General Medical } \\
\text { Degree }\end{array}$ \\
\hline Year of Obtaining the General Medical Degree & Frequency & Percent \\
\hline $\mathbf{1 9 9 4}$ & 1 & 2.4 \\
$\mathbf{1 9 9 7}$ & 1 & 2.4 \\
\hline $\mathbf{2 0 0 3}$ & 1 & 2.4 \\
\hline $\mathbf{2 0 0 5}$ & 3 & 7.3 \\
\hline $\mathbf{2 0 0 7}$ & 1 & 2.4 \\
\hline $\mathbf{2 0 0 8}$ & 1 & 2.4 \\
\hline $\mathbf{2 0 0 9}$ & 2 & 4.9 \\
\hline $\mathbf{2 0 1 0}$ & 4 & 9.8 \\
\hline $\mathbf{2 0 1 1}$ & 2 & 4.9 \\
\hline $\mathbf{2 0 1 2}$ & 4 & 14.6 \\
\hline $\mathbf{2 0 1 3}$ & 6 & 9.8 \\
\hline $\mathbf{2 0 1 4}$ & 4 & 14.6 \\
\hline $\mathbf{2 0 1 5}$ & 6 & 7.3 \\
\hline $\mathbf{2 0 1 6}$ & 3 & 7.3 \\
\hline $\mathbf{2 0 1 7}$ & 3 & 7.3 \\
\hline Total & 3 & 100 \\
\hline & 41 & \\
\hline
\end{tabular}

\begin{tabular}{lcc}
\hline Table 2. Descriptive Statistics Related to the Length of Residency & \\
\hline Length of Residency & Frequency & Percent \\
\hline One year & 8 & 19.5 \\
Two years & 14 & 34.1 \\
\hline Three years & 12 & 29.3 \\
\hline Four years & 7 & 17.1 \\
\hline Total & 41 & 100 \\
\hline
\end{tabular}

number of correct answers was 12, the least number of correct answers was 1.

Based on the results of the Table 4 , out of 41 subjects, 34 (82.9\%) people were unaware of the effective dose of Xrays in brain CT scan and 7 (17.1\%) people identified the appropriate dose. Results of other imaging methods can be interpreted in the same way.

Research results in response to the question whether radiology residents of Kermanshah educational centers are aware of the possible dangers of ionizing radiation. The questions in the section on awareness of the potential dangers of ionizing radiation include 4 questions. Based on the information obtained from the questionnaire, the descriptive statistics of the knowledge of radiology residents about the possible dangers of ionizing radiation are as follows:

Based on the results, the number of research units (residents) is 41 and the mean score of residents' awareness about the possible dangers of ionizing radiation is 1.70 out of 4 with a standard deviation of 1.03 of the 4 questions related to awareness of possible risks, the highest number of correct answers is 3 answers, the least number of correct answers is 0 . The percentage of the radiology resident's knowledge about potential risk of the ionizing radiation are as follows Table 5 .

\section{Discussion}

According to the results, 11 radiology residents were aware of the average natural background radiation and 30 of them (73.2\%) gave incorrect answer. Regarding the approximate effective dose received by a patient in a PA position of chest $\mathrm{x}$-ray, $19.5 \%$ (8 subjects) were aware. In various studies, this rate of awareness was different. In a study by John Ryan in Turkey, 23\% of residents and radiographers were aware (1), in Zakeri et al. (Iran), 33\% of specialist physicians were aware (6), in Lee et al. in Hong Kong, $32 \%$ of medical practitioners were aware (2) as well as $26 \%$ of residents in the study of Divrik Gokce et al. (4) were aware, one of the reasons for the low percentage in this study could be the low number of years of specialized activity of residents. On the other hand, regarding the percentage of awareness about approximate dose in bilateral view of chest X-ray, in some studies, including Ayşegül Yurt, 13\% of subjects were aware of effective dose of chest X-ray for adults (5). In our study, $97.6 \%$ (40 people) of the studied community were fully aware of the sensitivity of children age group to radiation, while none of the previous studies have examined it.

In this study, the knowledge about absorbed dose parameters was investigated based on the effect of X-rays received on chest X-ray in PA, that some of results are as below: in abdominal CT scan, $12.2 \%$ was aware, while in the John Ryan and Azmoonfar et al.'s study, it was $72 \%$ and $2.8 \%$, respectively $(1,9)$; in the brain and chest CT scans, $17.1 \%$ and $2.4 \%$ of subjects were aware, respectively, while in Azmoonfar et al. they were $2.8 \%$ and $1 \%$, respectively (9). In plain radiography, skulls in PA and some lower and upper organs were examined, where the awareness was $17.1 \%$ and $7.3 \%$, respectively, while in Azmoonfar et al.'s study, it was 80.2\% and $43.2 \%$, respectively, which indicates greater awareness of general practitioners and residents. Also, in the data obtained from the awareness about absorbed dose of fluoroscopic (dye) images according to Table 2, for example in barium enema, the awareness rate was $4.9 \%$ which was higher compared to other studies including Azmoonfar et al. $(0.9 \%)(9)$.

In the results of the study, $31.7 \%$ of the residents believed that MRI imagg examines were also accompanied by ionizing radiations, the frequency in the studies of Lee was 


\begin{tabular}{|c|c|c|c|c|c|c|c|c|}
\hline $\begin{array}{l}\text { Attending a Training } \\
\text { Course }\end{array}$ & Frequency & Percent & $\begin{array}{c}\text { Residents' Opinion } \\
\text { About Attending a } \\
\text { Course }\end{array}$ & Frequency & Percent & $\begin{array}{l}\text { Residents' View About } \\
\text { the Time of Attending } \\
\text { the Training Course }\end{array}$ & Frequency & Percent \\
\hline Yes & 1 & 2.4 & Agree & 39 & 95.1 & $\begin{array}{l}\text { During general medical } \\
\text { education }\end{array}$ & 13 & 31.7 \\
\hline No & 40 & 97.6 & Disagree & 2 & 4.9 & During residency & 27 & 65 \\
\hline Total & 41 & 100 & Total & 41 & 100 & After residency & 1 & 2.4 \\
\hline \multicolumn{3}{|l|}{ Variable } & \multicolumn{3}{|c|}{ Percentage of False Answers (Frequency) } & \multicolumn{3}{|c|}{ Percentage of True Answers (Frequency) } \\
\hline \multicolumn{3}{|l|}{ Question 1} & \multicolumn{3}{|c|}{73.2 (30 individuals) } & \multicolumn{3}{|c|}{26.8 (11 individuals) } \\
\hline \multicolumn{3}{|l|}{ Question 2} & \multicolumn{3}{|c|}{80.5 (33 individuals) } & \multicolumn{3}{|c|}{19.5 ( 8 individuals) } \\
\hline \multicolumn{3}{|l|}{ Question 3} & \multicolumn{3}{|c|}{2.4 (1 individuals) } & \multicolumn{3}{|c|}{97.6 (40 individuals) } \\
\hline \multicolumn{3}{|l|}{ Brain CT scan } & \multicolumn{3}{|c|}{82.9 (34 individuals) } & \multicolumn{3}{|c|}{ 17.1 (7 individuals) } \\
\hline \multicolumn{3}{|l|}{ Abdominal CT scan } & \multicolumn{3}{|c|}{87.8 (36 individuals) } & \multicolumn{3}{|c|}{12.2 (5 individuals) } \\
\hline \multicolumn{3}{|l|}{ Chest CT scan } & \multicolumn{3}{|c|}{97.6 (40 individuals) } & \multicolumn{3}{|c|}{2.4 (1 individuals) } \\
\hline \multicolumn{3}{|l|}{ US } & \multicolumn{3}{|c|}{31.7 (13 individuals) } & \multicolumn{3}{|c|}{68.3 (28 individuals) } \\
\hline \multicolumn{3}{|l|}{ MRI } & \multicolumn{3}{|c|}{31.7 (13 individuals) } & \multicolumn{3}{|c|}{68.3 (28 individuals) } \\
\hline \multicolumn{3}{|l|}{ PET head } & \multicolumn{3}{|c|}{87.8 (36 individuals) } & $12.2(5 \mathrm{in}$ & viduals) & \\
\hline Organs and bones & & & $92.7(38$ & lividuals) & & $7.3(3 \mathrm{inc}$ & viduals) & \\
\hline Skull & & & $82.9(34$ & lividuals) & & 17.1 ( 7 in & viduals) & \\
\hline Lumbar vertebrae & & & $95.1(39$ & ividuals) & & $4.9(2 \mathrm{in}$ & viduals) & \\
\hline Hip joint & & & $85.4(35$ & lividuals) & & 14.6 (6 in & ividuals) & \\
\hline Intravenous pyelography & & & $87.8(36$ & lividuals) & & $12.2(5 \mathrm{in}$ & viduals) & \\
\hline Barium swallow \& meal & & & $82.9(34$ & lividuals) & & 17.1 ( 7 in & viduals) & \\
\hline Barium follows through & & & $87.8(36$ & lividuals) & & $12.2(5 \mathrm{in}$ & viduals) & \\
\hline Barium enema & & & $95.1(39$ & ividuals) & & $4.9(2 \mathrm{in}$ & viduals) & \\
\hline
\end{tabular}

\begin{tabular}{lcc}
\hline Table 5. Percentage of the Knowledge of Radiology Residents About Possible Risks of Ionizing Radiation & \\
\hline Variable & Percentage of False Answers (Frequency) & Percentage of True Answers (Frequency) \\
\hline Question 18 & 68.3 (28 individuals) & 31.7 (13 individuals) \\
Question 19 & 51.2 (21 individuals) & 48.8 (20 individuals) \\
Question 20 & $22(9$ individuals) & 78 (32 individuals) \\
Question 21 & 87.8 (36 individuals) & $12.2(5$ individuals) \\
\hline
\end{tabular}

34\% (2), in Divrik Gokce et al. was 14.3\% (4), in Azmoonfar et al. was 35.8\% (9), and in the Faggioni study, it was showed that $10.9 \%$ of the study population thought that MRI and ultrasound imaging tests require even greater doses than a chest X-ray (10). In addition, unfortunately only $12.2 \%$ of residents were aware about the absorbed dose of PET scan (positron radiation), while the reported rate in the John Ryan study was 33\% (1). In another part of the study, the awareness of radiology residents about the dangers of ionizing radiation and the probability of cancer in people were investigated. Awareness about the possibility of cancer as a result of brain and abdominal CT scan was $31.7 \%$ and $48.8 \%$, respectively, while it was $33.5 \%$ and $32.7 \%$ in the study of Divrik Gokce et al. (4). Generally, in the study of Sidwell et al., $41.8 \%$ of the subjects believed that CT scan increased the risk of cancer due to the high absorbed dose of ionizing radiation (11). Also, regarding the question whether there are differences between the parameters of CT used 
for adults and children, 9 (22\%) subjects gave the wrong answer, lack of knowledge of residents about the maximum and minimum radiation parameters has been a factor in choosing the right option, while in the Divrik Gokce et al.'s study, $96 \%$ of subjects gave the correct answer (4).

\subsection{Conclusions}

According to the findings, the level of knowledge of radiology of Kermanshah University of Medical Sciences is at an inappropriate level. Therefore, in order to raise the awareness of radiology assistants, some training workshops on the importance and requirements of radiation and the amount of absorbed dose in patients should be held, because the radiology department, as one of the most important para-clinical units, has special and important responsibility for patients.

\section{Supplementary Material}

Supplementary material(s) is available here [To read supplementary materials, please refer to the journal website and open PDF/HTML].

\section{Acknowledgments}

The authors gratefully acknowledge the Student Research Committee and Research Council of Kermanshah University of Medical Sciences.

\section{Footnotes}

Authors' Contribution: Study concept and design: S.A; Acquisition of data: S.A; Analysis and interpretation of data: M.ZH; Drafting of the manuscript: S.A; Critical revision of the manuscript for important intellectual content: M.T; Statistical analysis: S.A\& M.ZH; Administrative, technical, and material support: M.ZH \& M.T; Study supervision: M.ZH

Conflict of Interests: The authors declare that there is no conflict of interest.

Ethical Approval: The study was approved by the Human Ethics Committee of Kermanshah University of Medical Sciences (Code: KUMS.REC.1396.204).
Funding/Support: The study was financially support by Kermanshah University of Medical Sciences (Grant Number. 96250).

\section{References}

1. Ramanathan S, Ryan J. Radiation awareness among radiology residents, technologists, fellows and staff: where do we stand? Insights Imaging. 2015;6(1):133-9. doi: 10.1007/s13244-014-0365-x. [PubMed: 25412827]. [PubMed Central: PMC4330233].

2. Lee RK, Chu WC, Graham CA, Rainer TH, Ahuja AT. Knowledge of radiation exposure in common radiological investigations: a comparison between radiologists and non-radiologists. Emerg Med J. 2012;29(4):306-8. doi: 10.1136/emermed-2011-200481. [PubMed: 21873321].

3. Yucel A, Alyesil C, Sim S. Physicians' knowledge about ionizing radiation and radiological imaging techniques: a cross-sectional survey. Acta Radiol. 2011;52(5):537-9. doi: 10.1258/ar.2011.100288. [PubMed: 21498311].

4. Divrik Gokce S, Gokce E, Coskun M. Radiology residents' awareness about ionizing radiation doses in imaging studies and their cancer risk during radiological examinations. Korean J Radiol. 2012;13(2):2029. doi: 10.3348/kjr.2012.13.2.202. [PubMed: 22438688]. [PubMed Central: PMC3303904].

5. Yurt A, Cavusoglu B, Gunay T. Evaluation of awareness on radiation protection and knowledge about radiological examinations in healthcare professionals who use ionized radiation at work. $\mathrm{Mol}$ Imaging Radionucl Ther. 2014;23(2):48-53. doi: 10.4274/mirt.00719. [PubMed: 24963445]. [PubMed Central: PMC4067876].

6. Zakeri F, Shakeri M, Rajabpour MR, Farshidpour MR, Mianji F. Physicians' Knowledge About Radiation Dose and Possible Risks of Common Medical Tests: A Survey in Iran. Radiat Prot Dosimetry. 2016;172(13):311-6. doi: 10.1093/rpd/ncw175. [PubMed: 27522049].

7. Gunalp M, Gulunay B, Polat O, Demirkan A, Gurler S, Akkas M, et al. Ionising radiation awareness among resident doctors, interns, and radiographers in a university hospital emergency department. $R a$ diol Med. 2014;119(6):440-7. doi: 10.1007/s11547-013-0374-8. [PubMed: 24356945].

8. Friedman AA, Ghani KR, Peabody JO, Jackson A, Trinh QD, Elder JS. Radiation safety knowledge and practices among urology residents and fellows: results of a nationwide survey. J Surg Educ. 2013;70(2):224-31. doi: 10.1016/j.jsurg.2012.10.002. [PubMed: 23427968].

9. Azmoonfar R, Faghirnavaz H, Younesi H, Morovati E, Ghorbani Z, Tohidnia MR. Physicians' Knowledge about Radiation Dose in Radiological Investigation in Iran.J Biomed Phys Eng. 2016;6(4):285-8. [PubMed: 28144598]. [PubMed Central: PMC5219579].

10. Faggioni L, Paolicchi F, Bastiani L, Guido D, Caramella D. Awareness of radiation protection and dose levels of imaging procedures among medical students, radiography students, and radiology residents at an academic hospital: Results of a comprehensive survey. EurJ Radiol. 2017;86:135-42. doi: 10.1016/j.ejrad.2016.10.033. [PubMed: 28027740].

11. Sidwell RA, Smith HL, Halsey JP, McFarlane MJ. Surgical Resident Radiation Knowledge, Attitudes, Practices, and Exposures. J Surg Educ. 2016;73(6):1032-8. doi: 10.1016/j.jsurg.2016.05.002. [PubMed: 27265210]. 